\title{
Research on product design method based on low carbon concept
}

\author{
Peixin $\mathrm{An}^{1^{*}}$, Kaining Meng²and Kunpeng $\mathrm{Li}^{3}$ \\ ${ }^{1}$ School of Art and Design, Xihua University, Chengdu, Sichuan, 610039, China $\quad{ }^{2}$ School of Art and Design, Xihua University, \\ Chengdu, Sichuan, 610039, China $\quad{ }^{3}$ School of Art and Design, Xihua University, Chengdu, Sichuan, 610039, China
}

\begin{abstract}
In the context of the new era, low-carbon environmental protection has become a fashion, and the concept of low-carbon has gradually become popular. This article starts from the research direction of product design, integrates the low-carbon concept into product design, and analyzes the problems in product design in China from the four stages of production, use, storage, transportation and recycling. In order to solve these problems, the guiding methods of product design under the low-carbon concept are given from the aspects of technology, materials, structure, and recycling, further demonstrate that the low-carbon concept promotes the development of product design.
\end{abstract}

\section{Introduction}

With the prosperity and development of social economy, energy consumption is becoming increasingly serious, climate change leads to the change of the earth's environment. Global cooperation on promoting a sustainable future raises three environmental issues: climate change, plastic pollution, and endangered species. Facing increasingly serious ecological problems, protecting the ecological balance of the environment has become the focus of the world. In the context of global efforts to promote energy conservation, emission reduction and low-carbon development, taking the road of sustainable development has become a promising way to curb global warming and climate change. As a product designer, it is imperative to change the previous design concept from the perspective of design and form new ecological thinking. In the process of product design, it is an effective method to guide product design from the perspective of low-carbon design concept and take balanced, scientific and quantitative means as the concept direction. Only by deepening the low-carbon design concept, can we promote the development of low-carbon design, open the future of low-carbon design, and realize the harmonious development of social economy and era environment.

\section{The time background of low-carbon design}

The term "low-carbon" is derived from the "Energy White Paper-Building a Low-Carbon Economy" issued by the United Kingdom in 2003. For the first time in this report, "low-carbon economy" is the primary goal of the UK's energy strategy. In recent years, the bad environment has seriously affected people's life. The greenhouse effect has intensified, the arctic glacier has melted, the Australian mountain fire has broken out, the marine garbage has entered the ecological circulation system, and the microplastics have entered the human biosphere. In 2018, the ISO organization released an internationally recognized ISO standard for quantifying a product's carbon footprint. According to the global footprint network, we are getting into ecological debt. If we continue to consume the earth's resources at the current rate, we will soon need the equivalent of 170 million earth resources. Product design advocates user-centered design and low-carbon design aims at "carbon reduction". The design idea complies with the changes of the times, takes the low-carbon concept as the core, considers the environmental factors and the product life cycle in a unified way, mitigates this situation by reducing the carbon footprint and carbon emission.

\section{Problems existing in domestic product design}

\subsection{Improper selection of production materials}

The selection of materials is the source of product design, and the quality of the materials affects the production of products. In the production of industrial products in China, materials with low cost, strong toxicity and poor degradability are widely used in order to improve economic benefits. Plastic bottles can be seen everywhere in life, there are considerable

*Corresponding author's e-mail: 1045853317@qq.com 
problems in the choice of materials for plastic bottles. The increasing use rate of plastic bottles leads to increasingly serious environmental pollution. Plastic bottles are difficult to be biodegraded, and it takes a long time to be degraded in its natural state. If incineration is chosen, a large amount of black smoke will be produced, and even highly toxic dioxins will produce secondary pollution; if the choice of landfill, not only occupy land resources, but also harm human health.

\subsection{The life cycle is too short}

With the advancement of science and technology, the speed of product upgrades has accelerated, and people's consumer psychology is also constantly changing. Consumers have never been satisfied in the process of using products. China should think from this, for example, why does the iPhone can stimulate people's desire to buy? Apple inc began to consider environmental protection issues from the perspective of technology production. The materials used in the products, such as Arensic-free glass, PC and highquality aluminum materials are easy to recycle. The durability of components such as batteries also extends the life of the product, the versatility of the product is reflected in the product design. In conclusion, science and technology promote production. In order to extend the life cycle of products, China's level of science and technology has yet to be improved.

\subsection{Difficult to store and transport}

China has a large population, and the production model is based on mass production. The products are too large and the structure is complicated, which will cause inconvenience during storage and transportation. For example, the transportation of bulky sofas and bookshelves with complicated structures has brought a lot of trouble to porters. Although designers are now paying attention to the space area in the process of product storage and transportation, they should also optimize the design scheme, consider the product structure, and make the space layout low-carbon and rational.

\subsection{Serious waste of resources}

The production of products must be accompanied by the recovery of products, which is also an important link that cannot be underestimated. For example, it is difficult to recycle used batteries again, and the waste of resources generated by mobile phones in the process of being eliminated is serious. For this reason, designers should not only consider the use of reusable or renewable materials in the design process, but also consider the redesign that can be achieved in the recycling phase. China has gradually popularized the common sense of "waste utilization", but some lay people may not know how to design and only satisfy their own pleasure. The products they design may not meet the low-carbon concept and lack practical significance.

\section{Analysis of product design methods under the low-carbon concept}

The use of raw materials, energy consumption, recycling, and waste disposal are still core issues that need to be addressed in the design. In the face of environmental pollution and excessive waste of resources, we must not only reduce carbon emissions at the source of product production, but also realize their use value and reduce unnecessary waste during the product recovery stage.

\subsection{Use of new low-carbon environmental protection materials}

Materials are the basis of design, and the properties of materials determine the possibilities of design. Designers should play the biggest role in the initial stage of the product, define the product selection materials, and consider the environmental impact of the entire product life cycle (LCA). As shown in figure 1, through the life cycle assessment, not only can "standard emission" be achieved, but also the environmental performance of the product can be well improved to make it compatible with the environment.

Compared with traditional materials, the new lowcarbon materials have less pollution and lower energy consumption. For example, natural bamboo, easy-torecycle plastics (HDPE, PP, PS, PVC), can convert natural resources into energy, etc. As shown in Figure 2 , this bamboo stool is designed with green bamboo materials combined with traditional bamboo craftsmanship to preserve the original color appearance. The special feature is the use of cement tenons, which is based on the characteristics of two original materials and is used in the combination of human relationships to design a stool. 


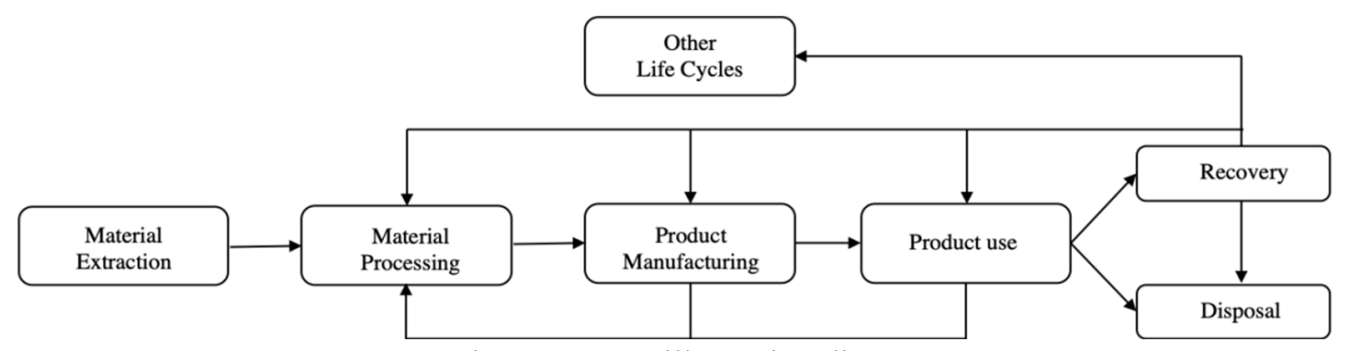

Figure 1. LCA illustration diagram

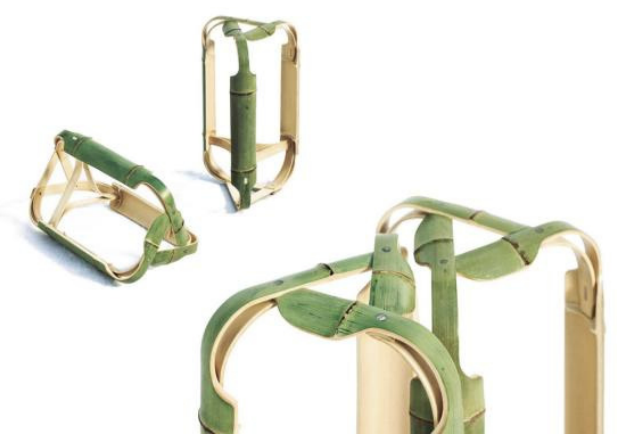

Figure 2. Bamboo stool design

(Photo credit: Prussia)

\subsection{Introduction of new low-carbon environmental technologies}

Science and technology are the primary productive forces, and technology is a powerful driving force for sustainable development. Scientific concepts guide new ideas in design, and integrating scientific concepts into design can realize new development of product design. Compared with other developed countries, China's scientific and technological level remains to be improved. As shown in Figure 3, the aerodynamic vehicle launched by Tata Motors of India uses low-carbon environmental protection technology to develop new energy by converting air into power to achieve zero emissions. China should learn from each other and seek common ground while shelving differences in the development of new technologies. The state can adopt corresponding encouragement policies to stimulate scientific and technological personnel's interest in developing patented products

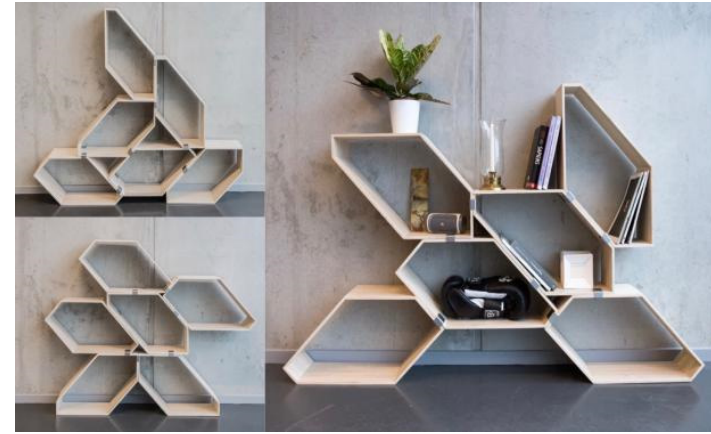

Figure 4. modular furniture design (Photo credit: Prussia)

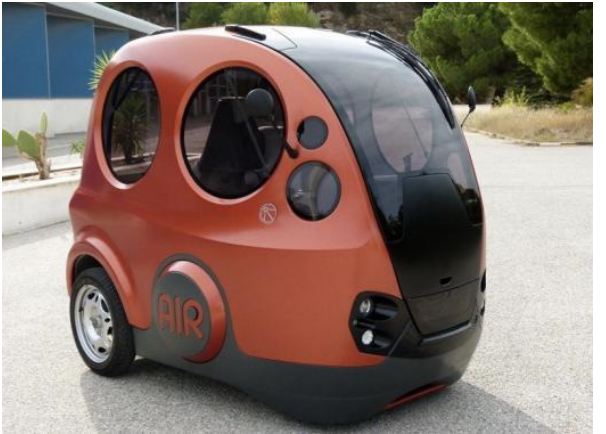

Figure 3. Air-powered car (Photo credit: Autohome)

and improve domestic environmental protection technology.

\subsection{Modularization of product structure}

Mies van der Rohe once put forward the design idea of "less is more", advocating flowing space, good function is the form of beauty, it is the extension of the structural modular design "less change should change more" design purpose. In order to achieve the relative independence of the product, change the structure, and make up as many products as possible with a small number of modules, while facilitating disassembly, transportation, and reorganization, while meeting various requirements in the most economical way. As shown in figure 4, the modular furniture design simply provides basic building blocks so that users can freely interact with the modules in a creative and functional way, which not only enhances the fun, but also effectively improves the space Utilization, this is an embodiment of design under the low-carbon concept.

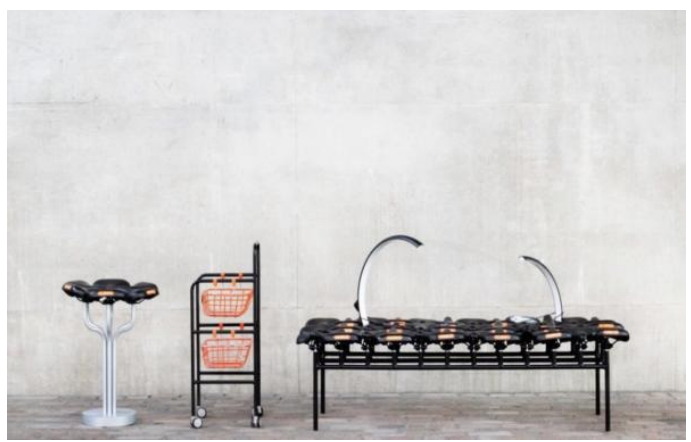

Figure 5. recycling of used bicycles (Photo credit: Prussia) 


\subsection{Waste redesign}

In order to realize the value of products, on the one hand, to promote the progress of new materials, new technology and new production; on the other hand, designers should pay attention to the sustainability and environmental protection of product follow-up development when designing products. When designing products, designers take the initiative to consider lowcarbon issues at the product level and develop lowcarbon living products and innovative solutions to replace the disadvantages of existing products. The lowcarbon concept has changed people's lives in a subtle way. It has become a fashionable way of life to redesign the wastes around us to meet our daily needs.

With the advancement of science and technology and the promotion of a low-carbon life, many new products have begun to be designed and produced using discarded materials. As shown in figure 5, designers recycle used bicycle parts to create furniture and make old products into treasure. Such products can be used multiple times in the original form. The product can be extended by recycling serving time, improving the efficiency of products and services.

\section{Conclusion}

In the context of the global environment that advocates energy conservation, emission reduction and low-carbon development, designers should implement low-carbon design concepts, fulfill their obligations and responsibilities, and promote the concept and value of low-carbon products. While meeting the needs of the targeted population, reduce carbon emissions and reduce the damage of products to the ecological environment. New materials, new technologies, new structures, and new recycling models provide effective guarantees for low-carbon design, and the creativity of designers brings new ideas to low-carbon design. This article analyzes the problems in different stages of the product design process, and proposes a guidance method for product design under the low-carbon concept. Through design, with sustainable development as the goal, adhering to the lowcarbon concept is effective for building an environmentfriendly and friendly society way.

\section{References}

1. Lang, L.J. (2019) Research on product design methods with low carbon concept as the core. J. Popular literature and art., 16: 111-112.

2. Li, F., Liu, D. (2017) Research on product design based on low-carbon design concept. J. Journal of science and technology., 17: 141.

3. Kan, Y.J. (2019) Analysis on influencing factors and countermeasures of product life cycle. J. Modern economic information., 06: 143.

4. Papanek, V. (2013) Design for the Real Word. CITIC, China.
5. Li, C., Zhang, G.W., Zhang,T. (2015) On the application of low-carbon design concept in product packaging design. J. China packaging industry., 06: 61-63.

6. Y, C.B., Xu, G.D. (2019) Analysis of sustainable design of products. J. Industrial design.,08: 113-114.

7. Yin, Y.J. (2008) Research on low-carbon design methods in commercial display design. J. Ecological economy., 34(04): 232-236. 